University of Tennessee Health Science Center

UTHSC Digital Commons

$5-2008$

\title{
A Mechanical and Histological Study of Functionally Graded Hydroxyapatite Implant Coatings
}

\section{Suzanne Kemp Coco}

University of Tennessee Health Science Center

Follow this and additional works at: https://dc.uthsc.edu/dissertations

Part of the Prosthodontics and Prosthodontology Commons

\section{Recommended Citation}

Coco, Suzanne Kemp , "A Mechanical and Histological Study of Functionally Graded Hydroxyapatite Implant Coatings" (2008). Theses and Dissertations (ETD). Paper 45. http://dx.doi.org/10.21007/ etd.cghs.2008.0054.

This Thesis is brought to you for free and open access by the College of Graduate Health Sciences at UTHSC Digital Commons. It has been accepted for inclusion in Theses and Dissertations (ETD) by an authorized administrator of UTHSC Digital Commons. For more information, please contact jwelch30@uthsc.edu. 


\title{
A Mechanical and Histological Study of Functionally Graded Hydroxyapatite Implant Coatings
}

\author{
Abstract \\ Ever since Dr. Brånemark discovered that titanium was biocompatible with bone, extensive research has \\ been done to improve the osseointegration of dental implants. As advances in medicine continue, the \\ average life span of the population is ever increasing. Today, people of all ages are investing more money \\ and time into dental treatment than ever before. Patients are becoming more educated on dental \\ treatment options and expect the best treatment possible. As a result, the replacement of missing teeth \\ with implants is becoming more and more commonplace in dental practices.
}

The purpose of the present study is to evaluate bone-implant interaction of functionally graded, thin film hydroxyapatite ( $\mathrm{HA})$ coatings in an animal model. The rationale for the graded coatings is such that they elicit different biological responses from different layers within the thin film (less than two microns). As such in this study, the graded coatings consist of an initial layering of crystalline HA coatings followed by the layering of an amorphous coating on the crystalline HA surface. Controls for this study are (a) plasma-sprayed HA, (b) amorphous HA, (c) crystalline HA, and (d) non-coated Titanium (Ti). The longterm goal is to improve the bone-implant interface leading to improved design and construction of implants and improved long term success. With this development it is expected that dental implants will be restored following shorter post-operative healing periods and patients will more quickly regain masticatory function resulting in the overall improvement of physical and mental health.

This study focused on mechanical and histological analysis of HA-coated and non-coated Titanium implants placed into the left femur of $\mathbf{4 0}$ male Sprague-Dawley rats. The rat was selected for this experiment because the specimen is affordable and historically proven to be a very good model for initial evaluation of the bone healing response to metal and metal coated implants. In vivo experimentation is preferred for these studies because bone wound healing is a complex process requiring the interaction of many cell types and factors. These conditions can not presently be predictably duplicated with in vitro experimentation.

In this study, two implants were placed into the left femur of each rat. At two time intervals (three weeks and nine weeks after implantation) 20 rats were euthanized and the femur containing the implants excised. A total of 40 implants were yielded at each time point. Since there were five groups (titanium, plasma sprayed $\mathrm{HA}$, amorphous $\mathrm{HA}$, crystalline $\mathrm{HA}$ and graded $\mathrm{HA}$ ), there were eight implants per group per time point $(40 / 5=8)$. Of these eight implants per time point per group, six were used for mechanical testing and two for histological evaluation. To evaluate the interfacial strength of the implants at the bone-implant interface, push-out test were performed. The evaluation of the bone response to implant was done using histological analysis.

At three weeks following implantation, there was no significant difference in the interfacial strength between the different implants. The interfacial strength had increased in all groups by nine weeks. The plasma sprayed HA implants had the greater interfacial strength followed by the graded HA, crystalline $\mathrm{HA}$, amorphous HA and titanium implants. At three weeks post implantation, the presence of connective tissue at the tissue-implant interface was noted for all implant groups tested. By nine weeks post implantation, all HA coated implants exhibited more bone formation at the bone-implant interface when compared to the non-coated Ti implants. The greatest response was seen in the plasma sprayed implants. A similar response was seen between the graded and crystalline as well as the amorphous and pure titanium. This study suggested that graded HA is a viable option for implant coatings. 


\section{Document Type}

Thesis

\section{Degree Name}

Master of Dental Science (MDS)

\section{Program}

Prosthodontics

\section{Research Advisor}

Joo Leng Ong, Ph.D.

\section{Keywords}

hydroxyapatite, functionally graded hydroxyapatite, titanium, osseointegration

\section{Subject Categories}

Dentistry | Medicine and Health Sciences | Prosthodontics and Prosthodontology 


\title{
A MECHANICAL AND HISTOLOGICAL STUDY OF FUNCTIONALLY GRADED HYDROXYAPATITE IMPLANT COATINGS
}

\author{
A Thesis \\ Presented for \\ The Graduate Studies Council \\ The University of Tennessee \\ Health Science Center
}

\author{
In Partial Fulfillment \\ Of the Requirements for the Degree \\ Master of Dental Science \\ From The University of Tennessee
}

By

Suzanne Kemp Coco, D.D.S.

May 2008 


\section{ACKNOWLEDGEMENTS}

I would like to express my gratitude to everyone who has helped me in my endeavor of pursuing a Master of Dental Science in Prosthodontics. To Dr. Joo Ong, without his immense knowledge and hard work, this research project would not have been possible. To my committee members, Drs. Dave Cagna, Tony Wicks, Paul Bland, Sunho Oh and Peter Yang for their advice and experience. To Drs. Wayne Chen and Mark Appleford, for their assistance with surgery, sample preparation, data collection and statistical analysis. Lastly, I must thank my family for their love and support. 


\begin{abstract}
Ever since Dr. Brånemark discovered that titanium was biocompatible with bone, extensive research has been done to improve the osseointegration of dental implants. As advances in medicine continue, the average life span of the population is ever increasing. Today, people of all ages are investing more money and time into dental treatment than ever before. Patients are becoming more educated on dental treatment options and expect the best treatment possible. As a result, the replacement of missing teeth with implants is becoming more and more commonplace in dental practices.

The purpose of the present study is to evaluate bone-implant interaction of functionally graded, thin film hydroxyapatite (HA) coatings in an animal model. The rationale for the graded coatings is such that they elicit different biological responses from different layers within the thin film (less than two microns). As such in this study, the graded coatings consist of an initial layering of crystalline HA coatings followed by the layering of an amorphous coating on the crystalline HA surface. Controls for this study are (a) plasma-sprayed HA, (b) amorphous HA, (c) crystalline HA, and (d) noncoated Titanium (Ti). The long-term goal is to improve the bone-implant interface leading to improved design and construction of implants and improved long term success. With this development it is expected that dental implants will be restored following shorter post-operative healing periods and patients will more quickly regain masticatory function resulting in the overall improvement of physical and mental health.
\end{abstract}

This study focused on mechanical and histological analysis of HA-coated and noncoated Titanium implants placed into the left femur of 40 male Sprague-Dawley rats. The rat was selected for this experiment because the specimen is affordable and historically proven to be a very good model for initial evaluation of the bone healing response to metal and metal coated implants. In vivo experimentation is preferred for these studies because bone wound healing is a complex process requiring the interaction of many cell types and factors. These conditions can not presently be predictably duplicated with in vitro experimentation.

In this study, two implants were placed into the left femur of each rat. At two time intervals (three weeks and nine weeks after implantation) 20 rats were euthanized and the femur containing the implants excised. A total of 40 implants were yielded at each time point. Since there were five groups (titanium, plasma sprayed HA, amorphous HA, crystalline HA and graded HA), there were eight implants per group per time point (40/5 $=8$ ). Of these eight implants per time point per group, six were used for mechanical testing and two for histological evaluation. To evaluate the interfacial strength of the implants at the bone-implant interface, push-out test were performed. The evaluation of the bone response to implant was done using histological analysis.

At three weeks following implantation, there was no significant difference in the interfacial strength between the different implants. The interfacial strength had increased in all groups by nine weeks. The plasma sprayed HA implants had the greater interfacial 
strength followed by the graded HA, crystalline HA, amorphous HA and titanium implants. At three weeks post implantation, the presence of connective tissue at the tissue-implant interface was noted for all implant groups tested. By nine weeks post implantation, all HA coated implants exhibited more bone formation at the bone-implant interface when compared to the non-coated Ti implants. The greatest response was seen in the plasma sprayed implants. A similar response was seen between the graded and crystalline as well as the amorphous and pure titanium. This study suggested that graded HA is a viable option for implant coatings. 
CHAPTER 1. INTRODUCTION

CHAPTER 2. REVIEW OF LITERATURE . . . . . . . . . . . 3

Osseointegration. . . . . . . . . . . . . . . . . . . . . . 3

Surface Modifications of Implants c . . . . . . . . . . . . . . . . . . . . 4

Hydroxyapatite . . . . . . . . . . . . . . . . . . 5

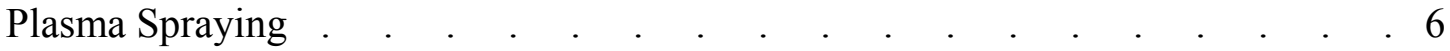

CHAPTER 3. RESEARCH OBJECTIVES . . . . . . . . . . . . . 11

Specific Aim I. . . . . . . . . . . . . . . . . . . . . . . . . . . . . . . .

Hypothesis I . . . . . . . . . . . . . . . . . . . . . . . .11

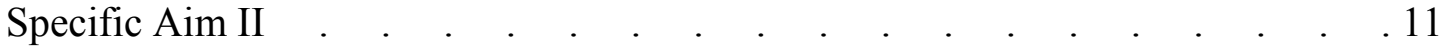

Hypothesis II . . . . . . . . . . . . . . . . . . . . . . . . . 11

CHAPTER 4. METHODS AND MATERIALS . . . . . . . . . . . 12

Materials Preparation (Implants) . . . . . . . . . . . . . . . . . . .12

Implantation . . . . . . . . . . . . . . . . . . . . . . . . $\quad .12$

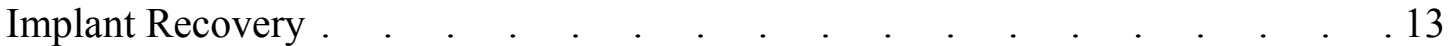

Mechanical Testing . . . . . . . . . . . . . . . . . . . . . . . $\quad .13$

Histological Analysis . . . . . . . . . . . . . . . . . . . . . . . .13

CHAPTER 5. RESULTS . . . . . . . . . . . . . . . . . . $\quad .15$

Push-Out Testing . . . . . . . . . . . . . . . . . . . . . .15

Histological Analysis . . . . . . . . . . . . . . . . . . . . . . . .15

CHAPTER 6. DISCUSSION . . . . . . . . . . . . . . . . . .27

CHAPTER 7. CONCLUSION . . . . . . . . . . . . . . . . . .30

LIST OF REFERENCES . . . . . . . . . . . . . . . . . . . .

VITA . . . . . . . . . . . . . . . . . . . . . . . . . . 


\section{LIST OF FIGURES}

Fig 1 Mean interfacial strengths of different implant surfaces three and nine weeks post implantation . . . . . . . . . . . . . . . . . . . . . 16

Fig 2 Titanium implants at three weeks post implantation . . . . . . . . 17

Fig 3 Titanium implants at nine weeks post implantation.$\quad$. $\quad . \quad$. $\quad . \quad$. 18

Fig 4 Plasma spray HA coated implants at three weeks post implantation . . . . 19

Fig 5 Plasma spray HA coated implants at nine weeks post implantation . . . 20

Fig 6 Amorphous HA coated implants at three weeks post implantation . . . . . 21

Fig 7 Amorphous HA coated implants at nine weeks post implantation $\quad . \quad$. $\quad .22$

Fig 8 Crystalline HA coated implants at three weeks post implantation $\quad . \quad$. $\quad .23$

Fig 9 Crystalline HA coated implants at nine weeks post implantation. . . . . . 24

Fig 10 Graded HA coated implants at three weeks post implantation $\quad . \quad$. . . 25

Fig 11 Graded HA coated implants at nine weeks post implantation. . . . . . . 26 


\section{CHAPTER 1. INTRODUCTION}

In the Old Testament book, Song of Songs it reads "Your teeth are like a flock of sheep just shorn, coming up from the washing. Each has its own twin; not one of them is alone." These words were spoken by King Solomon, expressing his admiration to his new bride. Reading this, you can see that sound, healthy teeth were highly valued by the early Hebrews. These words express the esthetic concepts of color, evenness, alignment, symmetry, and completeness (Lozada and Goodacre 2003). Teeth were considered objects of beauty, a symbol of strength and the loss of them was equated with weakness (Ring 1985).

Almost since the time man started loosing teeth there have been attempts to replace them. Various materials and methods have been utilized in this attempt. The Phoenicians, contemporaries of the Egyptians and Hebrews, attached "ivory teeth" to adjacent natural teeth using gold wire (Ring 1985). Between 1,000 and 200 B.C., the Etruscans, influenced by the Egyptian and Phoenician civilizations, made bridges to replace one or more missing teeth. The usual practice was to devise bands of soft, pure gold to surround remaining teeth. These bands carried artificial replacements for missing teeth and were soldered together. Some had pontics of human teeth, but in most cases, they were carved from calves and oxen teeth attached by riveting them to gold bands (Lozada and Goodacre 2003; Ring 1985).

Another method by which lost teeth were replaced was transplantation. Ambrose Pare is credited with being the first to mention transplantation as a way to replace teeth. In 1561, he reported that decayed teeth could be replaced with teeth extracted from another individual (Lozada and Goodacre 2003). In "The Surgeon - Dentist; or, Treatise on the Teeth" Pierre Fauchard discussed transplantation of teeth from one person to another. An Englishman, John Hunter, was also a strong promoter of tooth transplantation. He introduced a technique where teeth were extracted, boiled, and then re-implanted (Ring 1985).

While excavating in Honduras, an archeological team discovered a mandible of Mayan origin. The specimen, which dated around 600A.D, had three implanted artificial teeth carved from shells replacing three mandibular incisors. After being examined radiographically, it was determined that compact bone similar to that which forms around blade implants had formed around two of the shells implanted in the mandible (Ring 1985; Irish 2004). This may very well be the earliest example of any endosseous implant.

There have been several types of implants used throughout history. They can be classified by their position, constituent material, and design (Worthington et al. 2003). According to The American Dental Associations Current Dental Terminology, an implant is defined as "material inserted or grafted into tissue; dental implant-device specially designed to be placed surgically within or on the mandibular or maxillary bone as a means of providing for dental replacement; endosteal (endosseous); eposteal 
(subperiosteal); transosteal (transosseous)" (The American Dental Association 19952000).

Endosseous implants are placed into the bone through intraoral incisions in the mucoperiosteum. Some approximate the shape of a tooth root and others are flat plates, called blades. Most claim to incorporate within the living bone or osseointegrate (Worthington et al. 2003). Subperiosteal implants are non-osseointegrated frameworks that rest on the surface of the bone. The framework rests beneath the mucoperiosteum, with posts that penetrate the mucosa into the mouth (Worthington et al. 2003).

Transosseous implants consist of a plate that fits against the lower border of the mandible at the symphysis and has posts rising from it. This type is referred to as the transmandibular staple (Worthington et al. 2003). Among the different types of dental implants, endosseous implants are the most commonly used and are the fastest growing part of the dental implant market.

Many types of materials have been used for dental implants. These include vulcanized rubber, porcelain, and metals ranging from alloys of gold, titanium, and nickel-chrome-vanadium to commercially pure titanium (Worthington et al. 2003). According to a study by Cook et al. (1987), the choice of implant material is just as critical an element as the preparation site or the surgical insertion procedure. Decades of materials research have shown that commercially pure titanium (Ti) and its alloys are preferred materials for human hard tissue implantation because of their strength, comparatively low stiffness, light weight, and relative inertness (Cook et al. 1987). In addition to the different materials, implant designs also come in various forms. They may be either a tapered cylinder or a true cylinder, conforming more or less to the shape of a tooth root. Some implants may also be threaded or non-threaded (Worthington et al. 2003). 


\section{CHAPTER 2. REVIEW OF LITERATURE}

\section{Osseointegration}

The major breakthrough in implant success came when a physician named Per-Ingvar Brånemark and his colleagues were investigating wound healing. Since 1952, Dr. Brånemark and associates have studied the concept of tissue-integrated prostheses at the Laboratory of Vital Microscopy at the University of Lund, and subsequently at the Laboratory for Experimental Biology at the University of Göteborg (Brånemark 1983).

Osseointegration was defined by Brånemark and associates as a direct structural and functional connection between ordered living bone and the surface of a load-carrying implant (Raghavendra et al. 2005). The initial concept of osseointegration stemmed from vital microscopic studies of the bone marrow of the rabbit fibula, which was uncovered for visual inspection. The bone covering the prostheses was ground down to a thickness of only 10 to $20 \mu \mathrm{m}$. It was shown that circulation was maintained with very few signs of microvascular damage, which is the earliest and most sensitive indication of tissue injury (Brånemark 1983). They performed long-term in vivo microscopic studies of bone and marrow response to implanted Ti chambers of a screw-shaped design. These studies in the early 1960s strongly suggested the possibility of osseointegration since the chambers could not be removed from the bone once they have healed (Brånemark 1983).

In separate studies on the healing and anchorage stability of titanium tooth root implants, Brånemark et al. reported that when such an implant was introduced into the marrow cavity, and following an adequate immobilized healing period, a shell of compact cortical bone formed around the titanium implant without any apparent soft tissue intervention between the normal bone and the surface of the implant (Brånemark 1983). These studies showed that titanium was biocompatible and when surgically placed in bone, direct bone contact and complete healing occurred. This work led to development and introduction of titanium root form implants and the concept of osseointregration.

Osseointegration is now considered by the dental profession as mainstream treatment for replacing a single tooth up to a whole arch, or to simply stabilize a denture. This type of endosseous implant has become the most widely used implant in the world and will play an ever-increasing role in oral rehabilitation well into the $21^{\text {st }}$ century (Worthington et al. 2003).

Although the endpoint of osseointegration was clear, the mechanisms that lead to this state were somewhat of a mystery. Bone wound healing response at the implant surface is a complex process. With this in mind, Clokie and Warshawsky (1995) did an investigation with the purpose "to develop an animal model using the rat tibia and to design associated implant technology that would allow for detailed analysis by light and transmission electron microscopy of the developing interface between threaded Ti rootform implants and bone" (Clokie and Warshawsky 1995). They designed this study so it replicated as closely as possible to those used for human implant placement. 
Morphologic observations indicated that the placement of the titanium implants resulted in the bone adjacent to the implant becoming necrotic, resulting in resorption. New bone growth was observed from the old bone surfaces filling the threads with vascular channels and new lamellar bone.

This study showed that osseointegration was complete six weeks after placement of Ti implants. This technique provided a success rate of $95 \%$, comparable to those seen clinically in humans. The biocompatibility of titanium which allows the implant to osseointegrate, has been demonstrated previously by Brånemark. The osteoinductive influence of the titanium in directing bone development however, has not been determined. This study showed that new bone was deposited only on previously existing bone and extended toward the available space. There was no apparent relationship between the implant and the new bone, therefore suggesting that titanium is biocompatible, but not necessarily osteoinductive. The availability of the animal model that resembles the human situation has made it possible to analyze the interface between healing bone and titanium implants. This tibial bone model system can be used to develop new products that might enhance bone formation (Clokie and Warshawsky 1995).

The process of osseointegration does have a timeline. In a literature review by Raghavendra et al. (2005), the events involved in bone apposition occur in a series of discrete but overlapping stages. First, immediately after implantation, serum proteins adhere to the implant. During the first 3 days, mesenchymal cells attach and proliferate. By day 6, osteoid is produced, and in 2 weeks, matrix calcification is complete. At 3 weeks, remodeling of the bone is well under way. The most critical factor in successful osseointegration of an implant is primary stability in the bone at the time of placement, and this is easily achieved if bone is of adequate quality and volume (Raghavendra et al. 2005). Unfortunately, most patients seeking implantation possess bone of inadequate quality and/or quantity, and implants placed in poor bone quality and quantity are at greater risk of not establishing primary stability. Relative motion between the implant and the surrounding bone during the early healing phase is considered to be a high risk factor for early implant loss as failure of osseointegration occurs (Raghavendra et al. 2005).

\section{Surface Modifications of Implants}

One way to improve implants achieving primary stability is through surface modifications. There have been numerous studies on surface modifications of endosseous implants (Marinho et al. 2003; Ferguson et al. 2006). It has been shown through these studies that modifications to implant surface geometry and /or its chemistry is effective in accelerating bone formation and achieving reliable implant fixation in less than ideal situations. Modifications of machined threaded implant can be done by subtractive methods of surface modifications such as abrasion through blasting with titanium oxides or other soluble or resorbable biomaterials, or sandblasting with aluminous oxides. In one such study by Marinho and coauthors (2003), the differences in 
bone-implant contact (BIC) between sandblasted/acid-etched (SLA) and machinedsurface implants were evaluated using the rat tibia model. The BIC was evaluated at 5, 15,30 and 60 days. The result was that the sandblasted/acid-etched surface demonstrated a greater BIC percentage than the machined surface but only at 30 and 60 days of healing (Marinho et al. 2003).

Ferguson et al. (2006) did an evaluation of the interfacial strength of a chemicallymodified sandblasted and acid-etched Ti surface (SLA). In comparing SLA surfaces to chemically-modified sandblasted/acid-etched (modSLA) surfaces, removal torque testing performed after two, four, and eight weeks of bone healing suggested that the modSLA surface was more effective in enhancing the interfacial shear strength of implants than the SLA surface during the early stages of bone healing. It was also concluded that modSLA surfaces enhanced bone apposition when compared to SLA surfaces (Ferguson et al. 2006). Additive treatments, such as HA coatings and Ti plasma spraying, have also been reported (Raghavedra et al. 2005).

\section{Hydroxyapatite}

Bone is a specialized form of mineralized connective tissue consisting by weight of $33 \%$ organic matrix, of which $28 \%$ are type I collagen and the other $5 \%$ are noncollagenous glycoproteins, including osteonectin, osteocalcin, bone morphogenetic proteins, bone proteoglycan, and bone sialoprotein. The other $67 \%$ inorganic portion of the bone is made up of HA, which permeates the organic matrix.

The feature that distinguishes bone from other connective tissue is the mineralization (Ross et al. 1995) (Ong and Chan 1999). The mineral is calcium phosphate (CaP), in the form of HA crystals $\left[\mathrm{Ca}_{10}\left(\mathrm{PO}_{4}\right)_{6}(\mathrm{OH})_{2}\right]$. Since $\mathrm{HA}$ is found in bone, it is very biocompatible. It displays osteoconductivity, a property that encourages bone already formed to lie closely to, or adhere to, its own surface (Sun et al, 2001). Because CaP materials are ceramics, they are known for their poor mechanical properties, due to their brittle behavior. The rationale for HA coatings of 50-100 $\mu \mathrm{m}$ thickness originated from the desire to combine the strength of titanium with a bioactive HA surface (Ong et al. 2006). The use of HA-coated implants has been reported to stimulate bone healing. This has been attributed to HA's osteoconductive property, thus resulting in an improvement in the rate and strength of initial implant integration (Ong and Chan 1999; Ong et al. 2006). For this reason, HA is being studied as a surface modification on dental implants for improved osseointegration.

Various methods have been used to deposit the HA coatings on implants. Among these are dip coating-sintering, immersion coating, electrophoretic deposition, ion-beam sputter coating and dynamic mixing, hot isostatic pressing (HIP) and thermal spraying techniques such as plasma spraying, flame spraying, and high-velocity oxy-fuel (HVOF) combustion spraying (Sun et al. 2001). The current popular method of deposition of HA on titanium implants is by plasma spraying or arc plasma spraying. 


\section{Plasma Spraying}

Before plasma spraying takes place, the surface of the implant can be textured into microstructured, macrostructured, or porous morphologies. The microstructuring can be produced by grit blasting or beading. Grit blasting alters the smoothness of the metal surface to produce a roughness of approximately 3-6 $\mu \mathrm{m}$. This method has been shown to be successful in implant fixation and is currently the major method for implants in clinical use (Sun et al. 2001). Plasma spraying of HA usually takes place under normal atmospheric conditions, as opposed to the plasma spraying of some metallic powders during which a vacuum or an inert atmosphere is used to minimize oxidation. This process produces a coating with a thickness of greater than $30 \mu \mathrm{m}$ (Ong and Chan 1999).

The thermal spraying process utilizes a gas stream to carry HA powders, which are then passed through electrical plasma produced by a low-voltage, high-current electrical discharge (Ong and Chan 1999). An expansion of the gas results as the temperature increases (up to $30,000{ }^{\circ} \mathrm{C}$ ), causing the carrier gas stream to pass through the electric arc at approximately the speed of sound (Ong et al. 2006). The gas may be pure argon or a hotter plasma that is produced by a small addition of hydrogen or other gases. The semimolten HA powders are sprayed onto the titanium substrate, where they solidify. The use of thermal spraying is popular due to its simplicity, high deposition rates, and sufficiently low cost (Ong and Chan 1999).

However, there are problems associated with this process. Some of the problems reported by Ong et al. $(1999 ; 2006)$ include variations in bond strength between the coatings and the metallic substrates, alterations in HA structure due to the coating process, poor adhesion between the metallic substrates and the coatings, non-uniformity in coating thickness between vendors, alteration in structural and chemical properties during the coating process, and non-uniformity in coating density (Ong and Chan 1999; Ong et al. 2006).

Cheang and Khor (1996) attributed the problems associated with plasma spraying to improper melting of the feedstock, reproducibility, and satisfying biomedical requirements (Cheang and Khor 1996). Arc instabilities, which have an effect on the plasma jet outside the nozzle was also reported by Ong et al. (2006). Gas injection mode, spraying parameters, condition of the anode wall, and electrode design govern these instabilities. Only the spraying parameters (power, current, distance between nozzle and substrates, plasma work gas rate, carrier gas rate, powder feed rate, and spraying time) are variable, the rest are fixed with the chosen equipment. Plasma work gas composition is the most important spraying parameter, regulating the desired coating properties such as the crystallinity and coating thickness. By adding hydrogen to the argon gas in the plasma spraying process, coatings of a higher crystallinity will be produced. Adding nitrogen gas results in a thicker coating layer. By altering the gas composition of the plasma-spraying technique, amorphous or crystalline HA coating with varying thickness can be produced (Ong et al. 2006). 
Despite the concerns, plasma spraying is the current commercial process for depositing hydroxyapatite coatings on dental implants. In 1987, Cook et al. reported a study investigating the interface mechanical characteristics and histology of Commercially Pure (CP) Ti and plasma sprayed HA-coated Ti at 5, 10, and 32 week intervals. Two significant observations were made in this study: the HA-coated Ti implants were always more tightly bound than Ti implants (greater interface shear strength) and the establishment of significant interface strength was rapid for the HAcoated system. The HA-coated system was reported to develop five to eight times the mean interface shear strength of the uncoated, bead-blasted Ti implants (Cook et al. 1987).

HA-coated implants also showed the best histological results. By week 10, the interface was highly mineralized with direct apposition of bone to the HA-coated implant surface. There was no evidence of fibrous tissue at the interface and partially mineralized osseous tissue prevailed over the entire implant surface in areas of noncortical bone contact giving the implant the appearance of being totally encapsulated in bone. By week 32 , the osseous layer in areas of noncortical bone contact now appeared fully mineralized. Normal bone histologic features characterized the bone surrounding the HA-coated implants. It was concluded that the use of HA-coated Ti implants may be attractive for use in endosseous dental implant systems (Cook et al. 1987).

In comparing titanium plasma-sprayed (TPS) to plasma-sprayed HA implants in vivo, it was concluded that TPS and HA implants exhibited similar pull-out strength (Ong et al. 2004). In comparing plasma-sprayed HA coatings to CaP coatings produced by radiofrequency-sputtering, Ong et al. (2002) suggested that the $\mathrm{CaP}$ coatings produced bone responses similar to those of the plasma-sprayed HA coatings. Other studies on anodically modified, machined, and HA-coated implants after a healing period of 3, 6, and 12 weeks indicated a broad-based apposition of bone to the HA-coated and anodically roughened surfaces and a narrow bone contact to the machined surface (Zechner et al. 2003). It was concluded that HA-coated and anodically roughened implants provide a similar rate of bone-to-implant contact and that these surfaces may be of particular benefit due to their higher stability in maintaining preimplantation functional strength after implant healing (Zechner et al. 2003).

In a study by Sun et al. (2002), HA-coated implants were reported to exhibit a more rapid fixation and stronger bonding between host bone and the implant. The use of HA coatings were also reported to increase uniform bone ingrowth and/or ongrowth at the bone-implant interface (Sun et al. 2002). Despite excellent bone-implant interaction, one concern over the use of HA-coated implants is the resorption of HA coatings in a biological environment which may possibly lead to coating disintegration, loss of bond strength and fixation, and the threat of particulate debris formation (Sun et al. 2002). It was reported that the amorphous phase has a higher tendency to form at the coating-metal interface than in the coating (Sun et al. 2001). Bone growth occurs at a faster rate when the coating has a higher content of amorphous phase because of more rapid initial dissolution. As the bone grows toward the implant, the collagen incorporates the HA crystals in the body to produce a strong interface. However, the fast resorption of the HA 
coating may lead to the loss of the fixation and coating bonding resulting in loosening of the implant.

There have been six mechanisms of resorption hypothesized, but only two of them concern the clinical use of HA coatings. The first is the dissolution at neutral $\mathrm{pH}$, and the second is osteoclastic resorption of the coating as part of normal bone remodeling (Sun et al. 2002). Partial dissolution of the HA coating is essential to trigger bone growth, but exceedingly rapid dissolution leads to poor bone bonding and coating disintegration (Sun et al. 2002). In 2001, Sun et al. reported that the coating microstructure and properties can be a good predictor of the expected behavior in the body (Sun et al. 2001).

In a case report by Trisi et al. (2005) two mandibular HA coated implants were retrieved postmortem after 10 years of functional loading. They reported that the coatings of the implants examined were maintained on most of the surface. HA coating disappearance did not exceed $25 \%$ of the implant surface after 10 years of functional loading. It occurred on both the endosseous and coronal portion of the implant. They concluded that the absence of HA in a few areas did not compromise the direct contact between bone and the implant surface, since the bone achieved direct apposition to the underlying titanium surface (Trisi et al. 2005).

Aside from the concern with resorption, there is also a concern with the alteration of HA composition during deposition. According to Sun et al. (2001), the typical feedstock for HA coatings is a fully crystalline pure HA powder. After plasma spraying has occurred, both the purity and crystallinity of the HA decreases because of the decomposition of $\mathrm{HA}$ at high temperature and the rapid cooling rate. New phases appear in the HA coating, including an amorphous phase, tricalcium phosphate, tetracalcium phosphate, and calcium oxide. The calcium oxide phase is not biocompatible and should be avoided (Sun et al. 2001). To obtain HA coatings with predictable properties, both the purity and the crystallinity should be effectively designed. For this to occur, both the spray parameters and the quality of the original feedstock HA powders should be strictly controlled. The general agreement is that the chemical purity of HA should be as high as possible $(\geq 90 \%)$ with a $\mathrm{Ca} / \mathrm{P}$ ratio of 1.67 (Sun et al. 2001). Most manufacturers follow this guideline to ensure predictable implant performance. However, there is no agreement on the crystallinity of the HA coating. Plasma spraying has the ability to produce crystalline coatings from $30 \%$ to $70 \%$. Under a normal deposition process, the crystallinity is approximately $65 \%$ (Ong et al. 2006). The measurement of the crystallinity has been mainly performed with x-ray diffraction and supplemented with infrared spectroscopy, where both the lower crystal perfection caused by cooling from high temperatures and an amorphous phase are considered (Sun et al. 2001). Early fixation could also be achieved with a high-crystalline, high-purity coating, which is probably because of the existence of residual stress, pores, and the small crystal size of the thermal spray coating. However, these coatings usually contain more unmelted or partially melted particles, which could also lead to lower bonding and cohesive strength (Sun et al. 2001). 
Studies have been done evaluating the crystallinities of hydroxyapatite coatings. Oh et al. (2005) stated that the influence of $\mathrm{CaP}$ and HA crystallinity on bone-implant osseointegration is not well established. In their study, the effect of HA coatings with different crystallinities on the interfacial strength and morphology at the bone-implant interface indicated significantly greater interfacial strength and bone contact length for implants with the $70 \%$ crystalline coating as compared to HA crystallinity of $30 \%, 50 \%$, and $90 \%$. Berube et al. (2005) indicated that the degree of crystallinity is important for the bioactivity of the HA surface. It was reported that the more crystalline HA the coating contains, the more resistant to dissolution. An increase in the concentration of the amorphous calcium phosphate and tricalcium phosphate tend to increase dissolution. Using sputtered deposition process to produce $0 \%$ (amorphous), $1.9 \% \pm 0.4 \%$ (crystalline) and $66.4 \% \pm 2.8 \%$ (crystalline) coatings, Berube et al. (2005) reported that osteoblast differentiation and function were similar on Ti and HA surfaces with $66.4 \%$ crystallinity. In addition, HA with $66.4 \%$ crystallinity exhibited superior osteoblast function when compared to amorphous and poorly crystalline HA surfaces. Similarly, Yang et al. (2005) reported that tissue responds differently to biomaterials of different crystallinities. Although no significant difference in albumin adsorption and initial osteoblast precursor cell attachment was observed for amorphous up to $70 \% \mathrm{HA}$ crystallinity, a significant lower albumin adsorption and osteoblast attachment was observed on HA surfaces with 100\% crystallinity (Yang et al. 2005).

In an in vivo study by Chang et al. (1999) using sand-blasted Ti and HA-coated Ti of $50 \%, 70 \%$, and $90 \%$ crystallinity, it was reported that all HA coatings decreased in thickness over the 26 weeks study period. Most noticeable decrease in coating thickness was observed during the first four weeks of implantation, with the $50 \%$ crystallinity showing the most resorption of all the coatings. It was also reported in the study that bone contact with $\mathrm{Ti}$ implants increased in a time-dependent pattern, whereas a sudden increase was noted for the HA-coated implants at the four week but reached a plateau at the 12 week mark. No significant difference in bone contact was observed for the HAcoated implant during the 26 week study. This observation suggested that HA-coated implants enhanced osseointegration in the early stage of bone healing and provided strong bone-bonding capacity, although Ti implants have about the same level of bone contact in the later stage of healing.

It has been observed in recent studies that bone responds differently to hydroxyapatite surfaces of different crystallinity (Oh et al. 2005). Some indicates higher bone activity with highly crystalline films, others suggesting that some amorphous phase in the coatings is desirable promoting a more stable interface with the biological environment. As stated previously, the most common means of applying HA to implants is by plasma spraying. This process produces a thick coating, typically between $79 \mu \mathrm{m}$ and $111 \mu \mathrm{m}$, with a high degree of crystallinity (Rabiei et al. 2005). Although HA has excellent biocompatibility properties, the brittleness of the HA coating often results in wear, cracking and fracture (Khor et al. 2003). Some studies have indicated that thin HA coatings $(2 \mu \mathrm{m})$ have a significantly greater coating-metal interfacial strength compared with commercially available thick $(70 \mu \mathrm{m})$ plasma-sprayed HA coatings (40 MPa vs. 9MPa) (Rabiei et al. 2005). 
Khor et al. (2003) reported that the approach to solving this problem is the development of a novel HA/Ti-6Al-4V functionally graded coating. These functionally graded materials (FGM) are a new generation of composites with a gradual compositional or structural variation. The graded structure FGM allow the integration of dissimilar materials such as ceramics and metals without severe internal stress and combine diverse properties into a single material system. The FGM shows excellent biocompatibility and bone-bonding ability, since the surface layer is HA. Excellent mechanical strength is contributed by Ti-6Al-4V phase (Khor et al. 2003). In this study by Khor et al. (2003), functionally graded hydroxyapatite (HA)/Ti-6Al-4V coatings were produced by plasma spraying, using specially developed HA-coated Ti-6Al-4V composite powders as feedstock. Their aim was to characterize the microstructure, phase composition, and mechanical properties of single-layered composite coatings and laminated FGC. Crosssectional microstructure revealed the FGC coatings to be relatively uniform and compact. No clear differences between two adjacent layers of different compositions were found, resulting in a reasonably uniform microstructure. This graded distribution can decrease the high thermal stress and improve the properties of coatings. X-ray diffractometry revealed the presence of HA and $\alpha$-Ti. No other calcium phosphate phases were found, only a bit of $\mathrm{CaO}$ phase. The tensile bond strength of the two-layered and three-layered FGC was much higher than the conventional HA coating on Ti-6Al-4V substrate.

In a study by A. Rabiei et al. (2005), hydroxyapatite films with graded crystallinity were prepared using a novel dual-ion beam sputtering in situ annealing process. These graded crystallinity films deposited using IBAD techniques exhibited better nanohardness and Young's modulus values than films that were prepared by sintering or sputtering and post-deposition annealing. The authors anticipate that these novel functionally graded films can improve the implant-tissue interface in next-generation dental implants. 


\section{CHAPTER 3. RESEARCH OBJECTIVES}

Replacing missing teeth with dental implants is becoming more and more commonplace. As the population ages, implants must be developed that will function longer. In vitro experiments have led us to hypothesize that dental and orthopedic implants coated with a new type of material that is similar in composition to bone mineral (nano-structured hydroxyapatite) will bond more rapidly and more completely to the bone when compared to non-coated Ti implants. The purpose of the present study is to evaluate bone-implant interaction of functionally graded, thin film hydroxyapatite (HA) coatings in an animal model. The rationale for the graded coatings is such that they elicit different biological responses from different layers within the thin film. As such in this study, the graded coatings consist of an initial layering of crystalline HA coatings followed by the layering of an amorphous coating on the crystalline HA surface. Controls for this study are (a) plasma-sprayed HA, (b) amorphous HA, (c) crystalline $\mathrm{HA}$, and (d) non-coated Ti. The long-term goal of this study is to improve the boneimplant interface leading to improved design and construction of implants and improved long term success. As such, the following specific aims and hypotheses for this study are:

\section{Specific Aim I}

To evaluate bone-implant interfacial strength associated with titanium and available HA coatings in a rat model.

\section{Hypothesis I}

An improvement in the ultimate interfacial strength of the implants can be achieved by having a layer of graded HA coatings. This hypothesis was tested by placing coated pins in the rat femur and push-out testing was performed at three weeks and nine weeks after implantation.

\section{Specific Aim II}

To histologically correlate the quality of interfacial bone response to interfacial implant strength for titanium and available HA coatings.

\section{Hypothesis II}

The quality of interfacial bone response to available HA coatings and titanium is correlated to the interfacial implant strength. Histological sections of the bone-implant interface will be evaluated at three weeks and nine weeks after implantation. 


\section{CHAPTER 4. METHODS AND MATERIALS}

\section{Material Preparation (Implants)}

Rods of grade two commercially pure titanium (President Titanium, Hanson, MA) of 0.125 inch diameter were machined to produce cylindrical implants $1.8 \mathrm{~mm}$ in diameter and $2.0 \mathrm{~mm}$ in length.

The implants were divided into five groups. Of these five groups, one group was left uncoated and each of the remaining four groups were coated with either a plasma sprayed HA, amorphous HA, Crystalline HA or graded coating (crystalline followed by amorphous) HA. The first four implant groups were used as the controls for this study.

\section{Implantation}

Forty Sprague-Dawley rats weighing approximately $250 \mathrm{~g}$ apiece were used for this study. All animal experiments were in compliance with U.S. Department of Agriculture programs and U.S. National Institutes of Health publication 86-23, Guide for the Care and Use of Laboratory Animals. Appropriate considerations were given to all policies, standards, and guidelines governing the proper use, care, handling, and treatment of animals. The study was approved by an institutional review board.

The animals were divided into five groups of eight, the first group having commercially pure titanium implants placed in the left femur, second group, plasma sprayed HA, third group, amorphous HA, fourth group, crystalline HA, and fifth group, graded crystalline HA implants. The rats were anesthetized with a premixed cocktail of ketamine, xylazine, and acetylopromazine $(8.5 / 1.7 / 0.2 \mathrm{mg} / \mathrm{kg}$ body weight). The cocktail was administered intramuscularly using $0.1 \mathrm{cc}$ of cocktail per $100 \mathrm{~g}$ body weight.

Under anesthesia, the hind left limb was shaved and cleaned with a povidone iodine solution. A $15 \mathrm{~mm}$ incision was made over the prominence of the femur bone. Using blunt dissection, the muscles were separated over the femur to expose the periosteum. After dissection of the periosteium, two transcortical holes were formed at intervals of 4 $\mathrm{mm}$ by drilling with a slow-speed $(500 \mathrm{rpm})$ dental hand- piece equipped with a $1.8 \mathrm{~mm}$ trephine bur. The implant sites penetrated into the marrow cavity of the femur. Profuse irrigation with physiologic saline was maintained throughout the drilling to minimize the temperature rise in the bone.

Cylindrical implants measuring $1.8 \mathrm{~mm}$ in diameter and $2 \mathrm{~mm}$ in length were placed

in each surgically prepared hole by tapping with a mallet until the top of the implant was flush with the cortical bone surface. The periosteium was reapproximated, the muscle replaced, and the skin closed using metal surgical staples. A total of 80 implants were used, two in each femur. The rats were allowed to recover from anesthesia in a warm 
environment while being observed. All animal were monitored twice daily, especially during the first week after surgery.

\section{Implant Recovery}

At two time intervals (three weeks and nine weeks post implantation) 20 rats (four from each group) were euthanized using carbon dioxide asphyxiation. Immediately after sacrificing the animals, the femur containing the implants were exposed. The bone was disarticulated at the hip and knee joints, and stored in normal saline solution. In preparation for testing, the excess tissue was removed from the bone-implant block. To evaluate the interfacial strength of the implants at the bone-implant interface, push-out testing was preformed. The testing was done within eight hours after sacrificing the animals. The implants used for the histological analysis of the bone-implant contact were fixed for eight hours in a $4 \%$ buffered paraformaldehyde solution.

\section{Mechanical Testing}

The ultimate interfacial strength of the implants at the bone-implant interface over time and treatment was determined using push-out testing conducted with an Instron mechanical tester (model 1125; Instron, Canton, MA). Immediately after sacrificing the animals, the femur containing the implants were stored in normal saline. Of the eight implants per time point per group, six were used for mechanical testing and two for histological evaluation. The six implants per time point per treatment were evaluated within four hours after sacrifice using a crosshead speed of $1 \mathrm{~mm} / \mathrm{min}$. The ultimate interfacial strength ( $\mathrm{s}$ ) was calculated using the formula $\mathrm{s}=\mathrm{P} / \mathrm{pdh}$, where $\mathrm{P}$ was the ultimate pull-out load $(\mathrm{N}), \mathrm{d}$ was the diameter of the implant $(\mathrm{mm})$, and $\mathrm{h}$ was the length of the implant $(\mathrm{mm})$ in bone. The Ultimate interfacial strengths for the different groups of implants were statistically analyzed using an analysis of variance (ANOVA), with Sheffe's procedure as a post-hoc test. Differences were considered significant at the $\mathrm{P}$ $<.05$ level.

\section{Histological Analysis}

A total of two implants per time point per treatment were used for histological evaluation of the bone-implant interface. The bone-implant specimens were recovered from the $4 \%$ buffered paraformaldehyde solution in which they were fixed. They were then trimmed to within $4 \mathrm{~mm}$ of the implant surface using an electric hand-piece (NSK Volvere GX, Model FC-35, Nakanishi Dental, Japan) and a diamond disc (Brasseler Dental Rotary Instruments, Savannah,GA).

Dehydration of the specimens was accomplished using a graded series of ethyl alcohols and three stages of clearing fluid (xylene) in tightly capped specimen jars. Infiltration was performed using a graded series of xylene and Osteo-Bed resins (Poly- 
sciences, Warrington, PA), followed by a catalyzed mixture of Osteo-Bed resin containing 1\% (wt/vol) of benzoyl peroxide. Embedding the specimens involved using a final catalyzed resin mixture of Osteo-Bed solution containing $2.5 \%(\mathrm{wt} / \mathrm{vol})$ of benzoyl peroxide. The specimens were then embedded in the final catalyzed resin mixture and placed under a curing lamp until final polymerization.

The embedded specimens were removed from the vials by breaking the glass. The specimens were trimmed of excess resin and sectioned using the Leco VC-50 precision diamond saw (Leco Co., St. Joseph, MI). The specimen sections were furthered reduced in size using an electric sander and decreasing grits of sandpaper (rough to fine). After placement of specimens on glass slides they were then stained using Paragon stain (purple for connective tissue), destained in acid alcohol (30\% ethanol in 1\% HCL), and counterstained in aqueous $1 \%$ alizarin red (for mineralized calcium). Longitudinal sections of the bone-implant specimens were prepared and examined under a stereo microscope. The specimens were then qualitatively analyzed. 


\section{CHAPTER 5. RESULTS}

\section{Push-Out Testing}

The mean ultimate interfacial strengths of the five implant groups, at three and nine weeks post implantation, are shown in Figure 1. There was no statistical difference noted between the five groups at three weeks following implantation. The interfacial strength of all groups had increased by week nine. The plasma sprayed hydroxyapatite implants exhibited the highest statistical interfacial strength (Group 2) among the five groups tested. No statistical difference was indicated for the crystalline hydroxyapatite coated (Group 4) and graded crystalline hydroxyapatite coated implants (Group 5). Similarly, no statistical difference was observed between the amorphous hydroxyapatite coated implants (Group 3) and the commercially pure titanium implants (Group 1).

\section{Histological Analysis}

Figures 2 to 11 show representative histological images of implant-bone interfaces at three and nine weeks post implantation. The qualitative analysis at three weeks indicated the presence of connective tissue at the tissue-implant interface for all implant groups tested. By nine weeks after implantation, all HA coated implants exhibited more bone formation at the bone-implant interface when compared to the non-coated Ti implants. The amount of bone at the bone-implant interface was greatest for the plasma-sprayed HA implants, followed by graded HA implants. The crystalline HA implant-bone interface was observed to have less bone formation when compared to the graded HA implant-bone interface, whereas the amorphous HA implant-bone interface was observed to have the least amount of bone formation among the HA groups tested. 


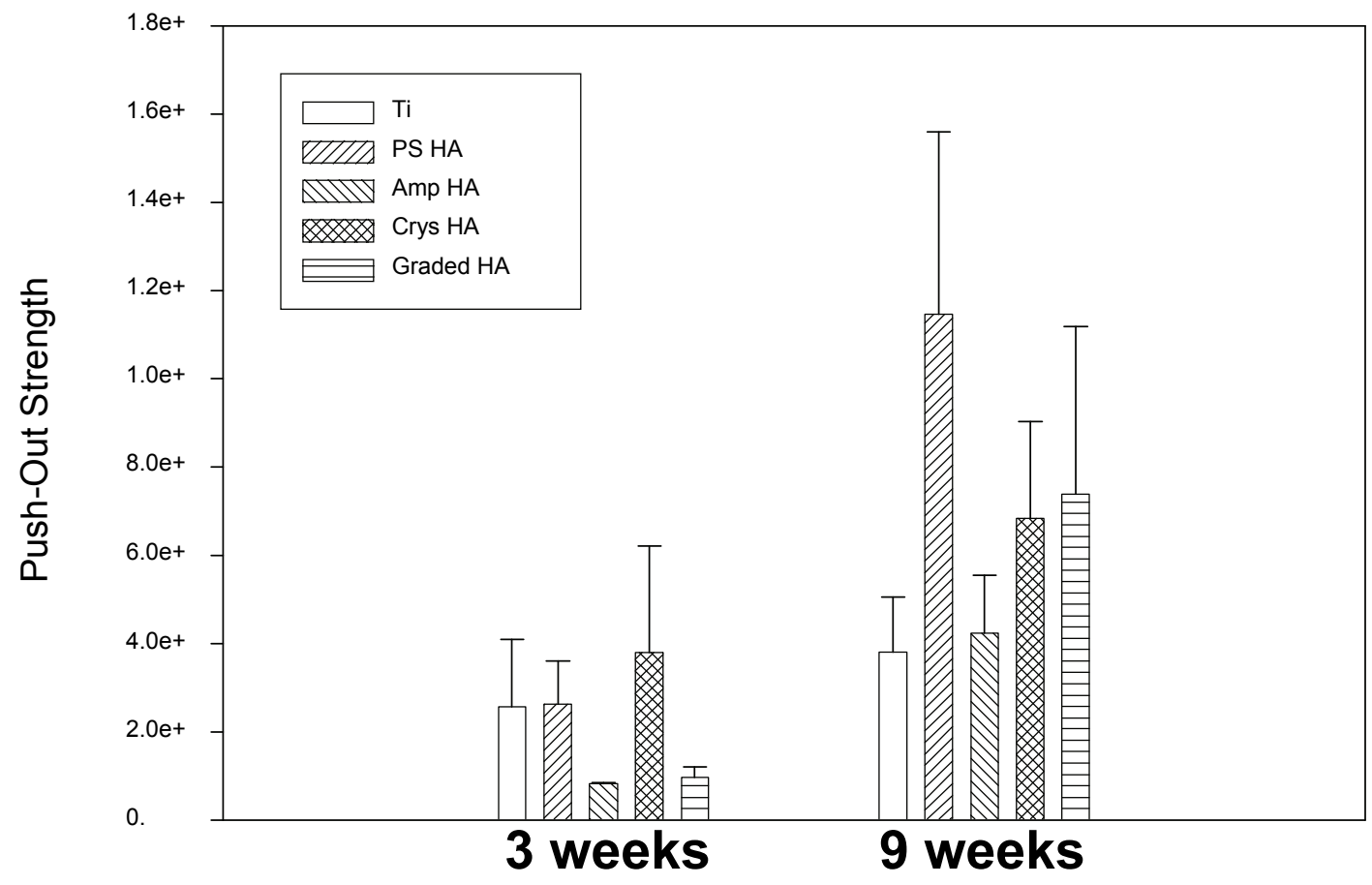

Fig. 1 Mean interfacial strengths of different implant surfaces three and nine weeks post implantation. 

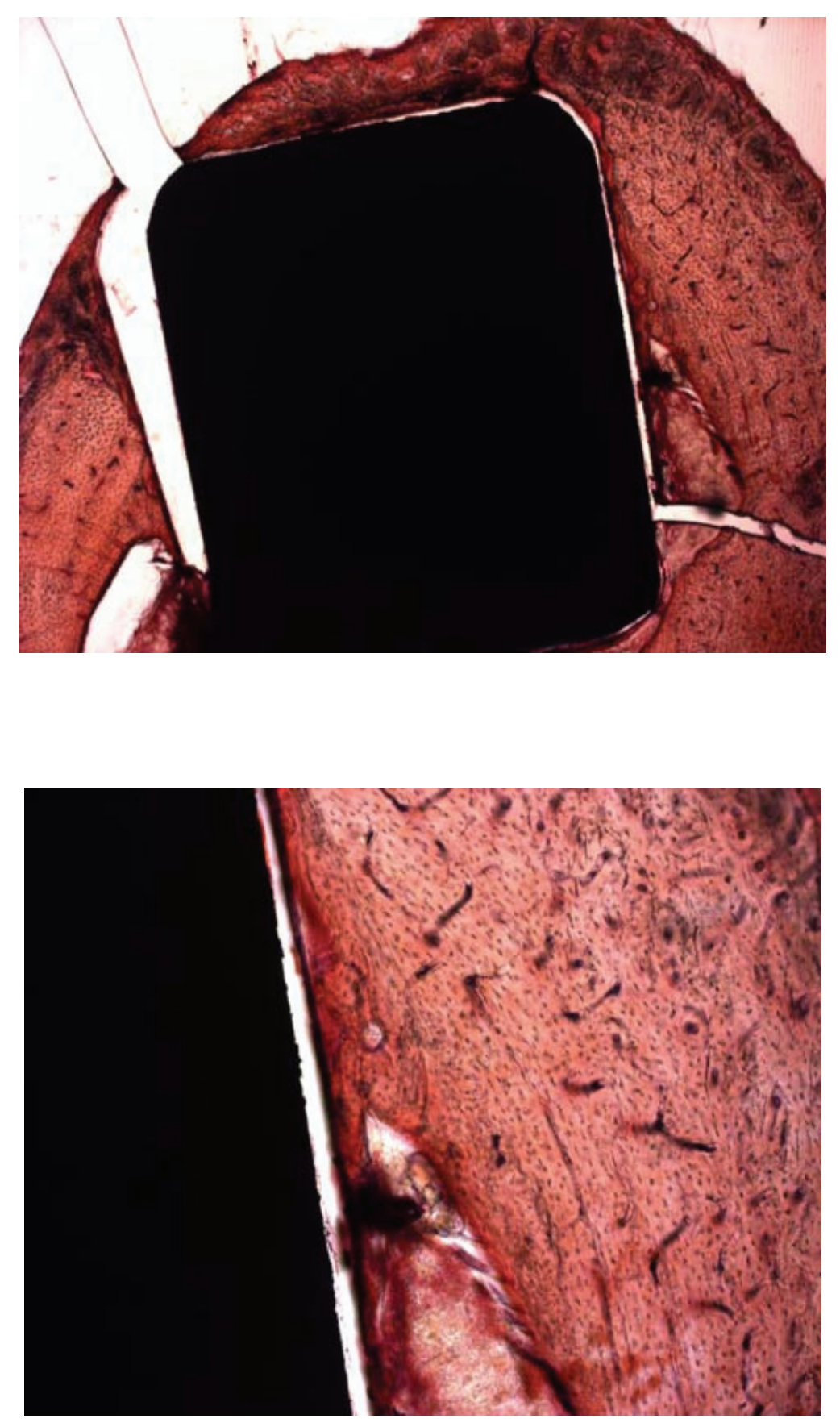

Fig. 2 Titanium implants at three weeks post implantation. 

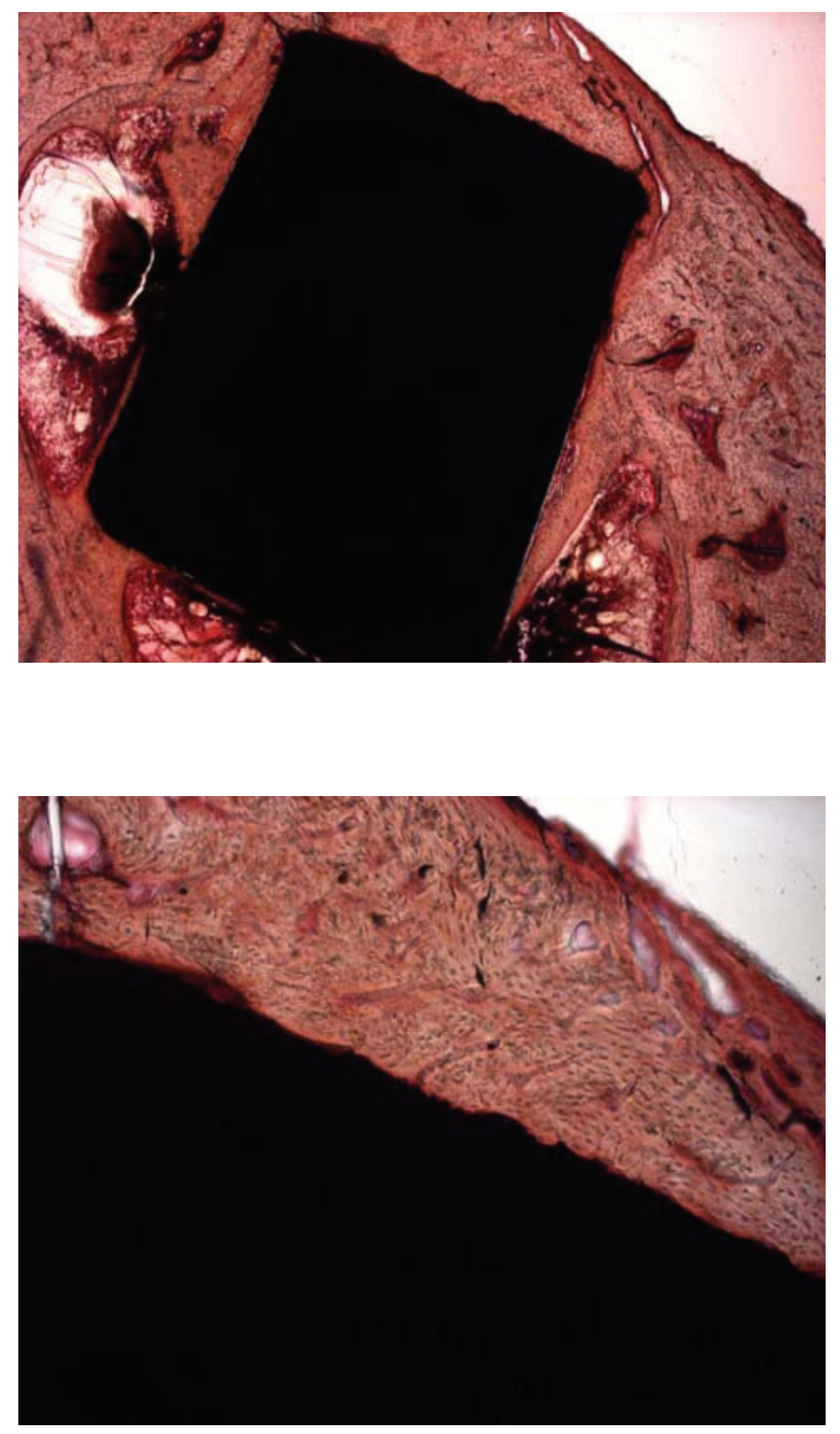

Fig. 3 Titanium implants at nine weeks post implantation. 

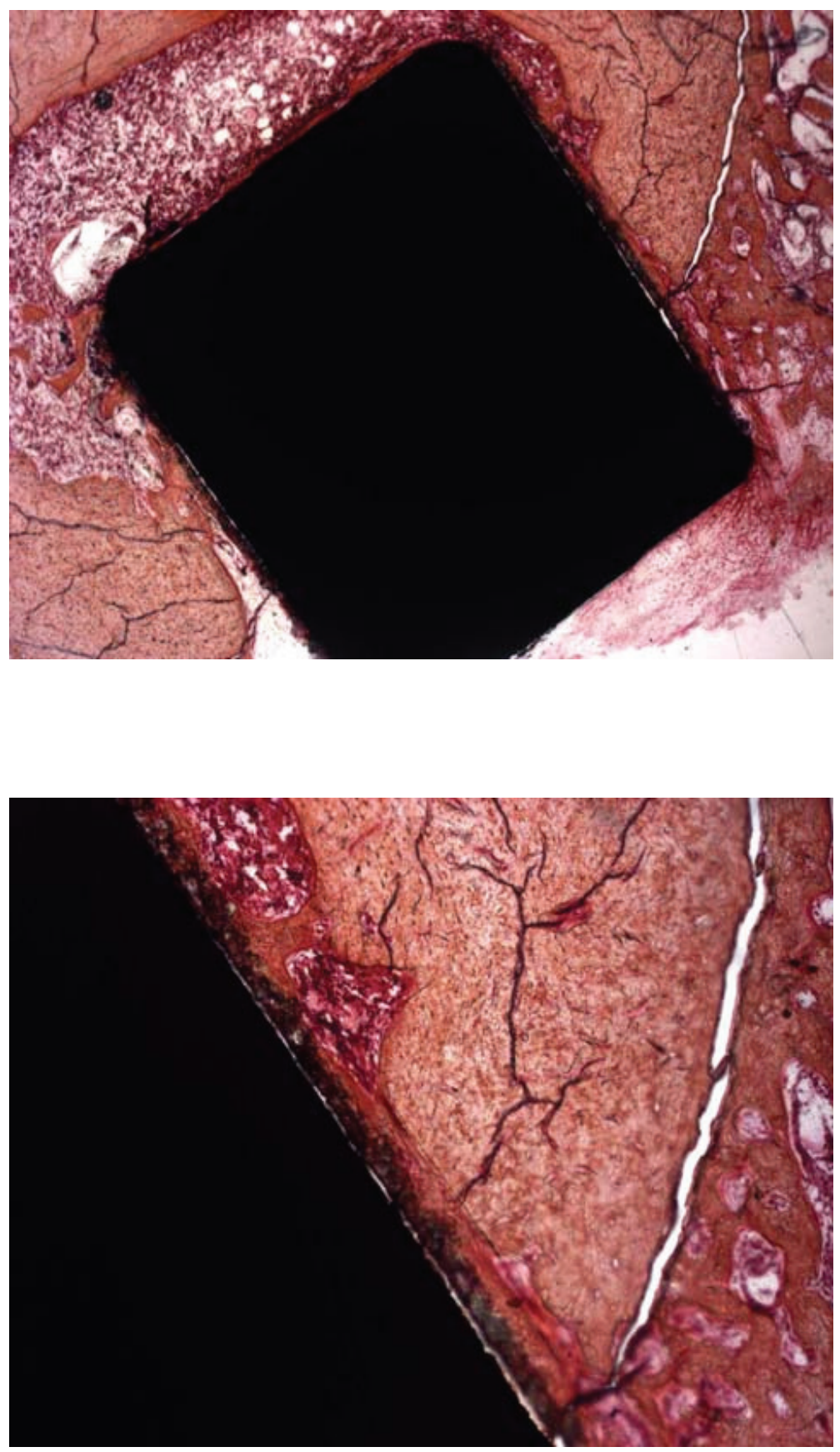

Fig. 4 Plasma spray HA coated implants at three weeks post implantation. 

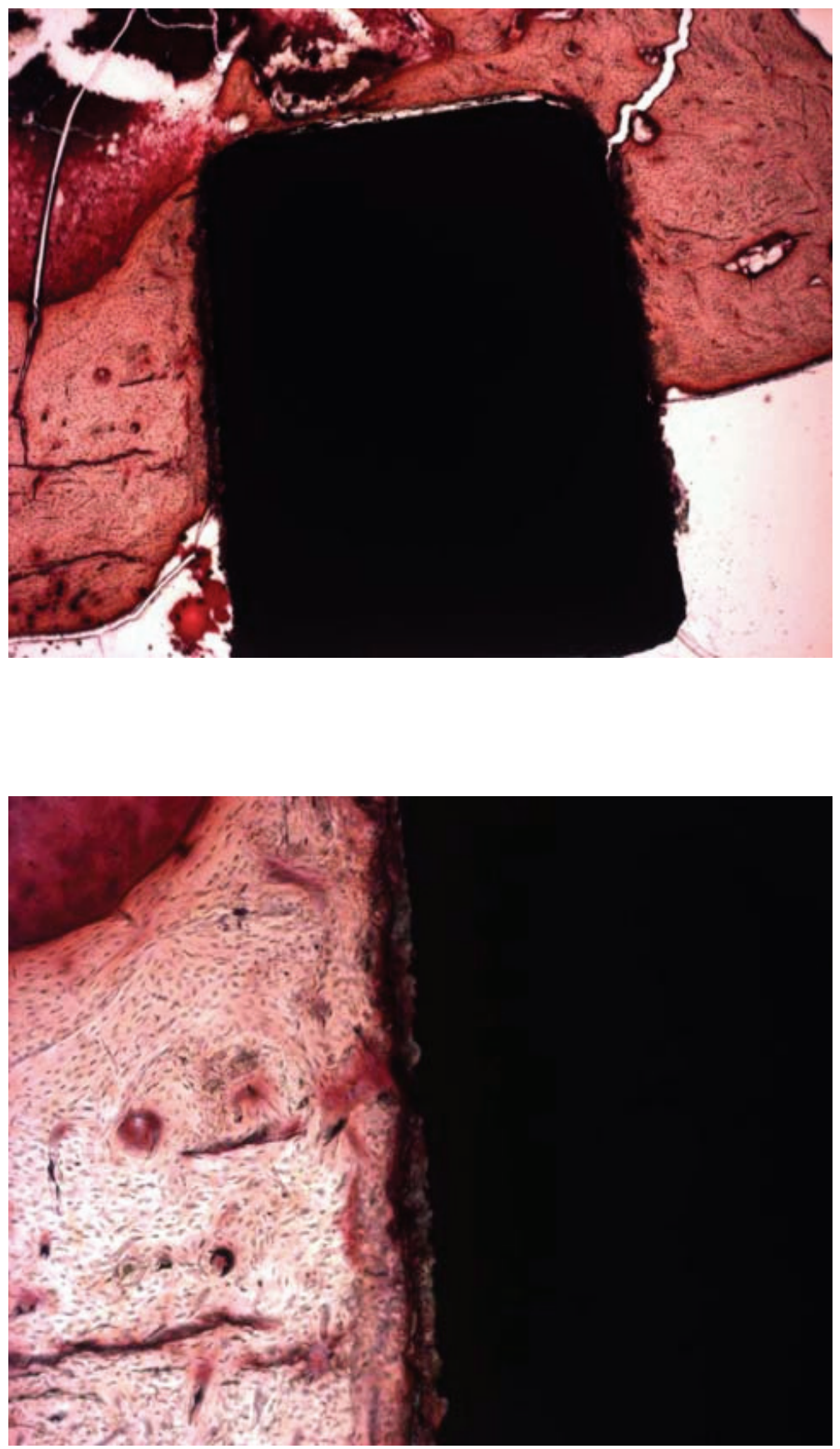

Fig. 5 Plasma spray HA coated implants at nine weeks post implantation. 

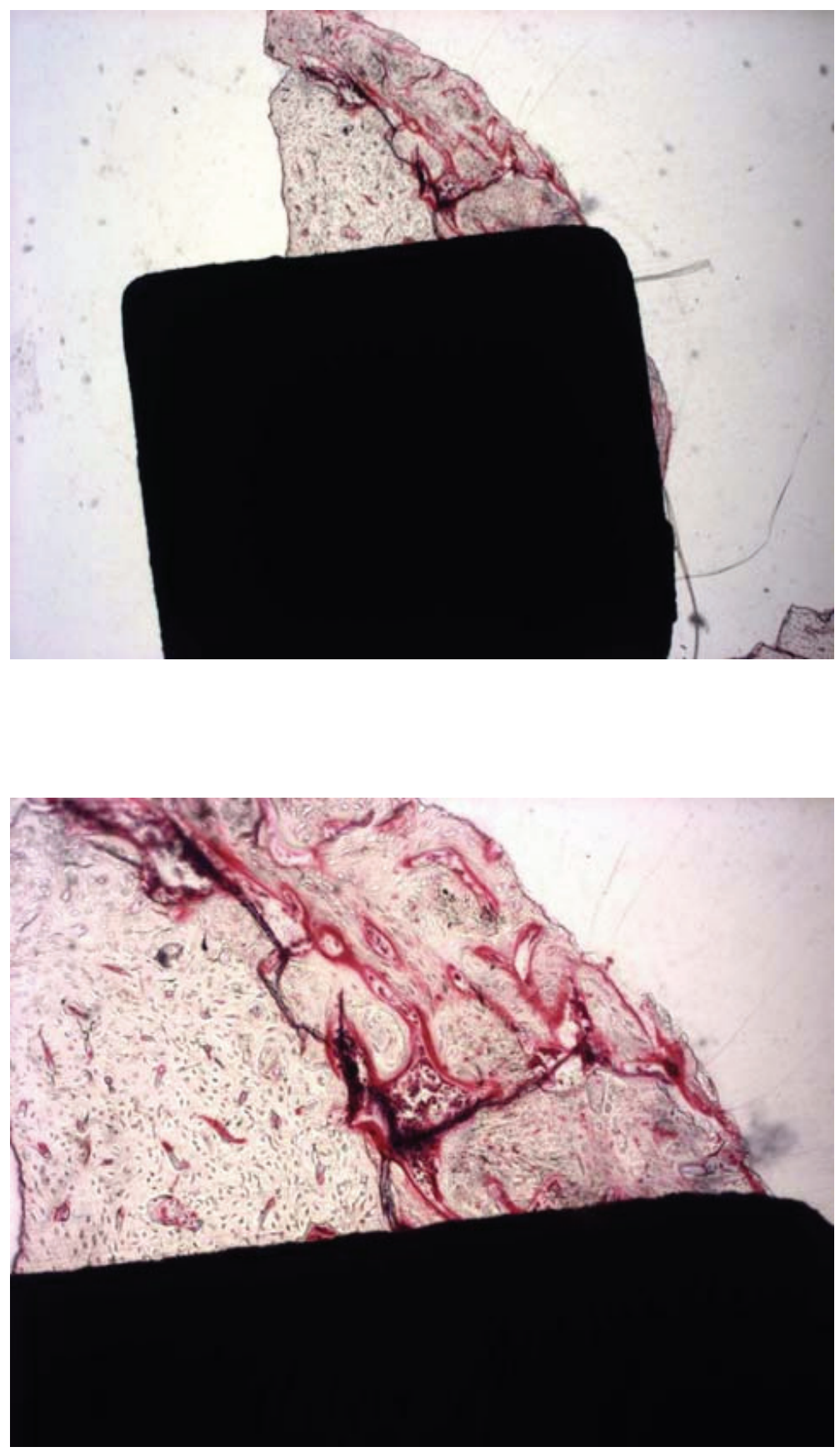

Fig. 6 Amorphous HA coated implants at three weeks post implantation. 

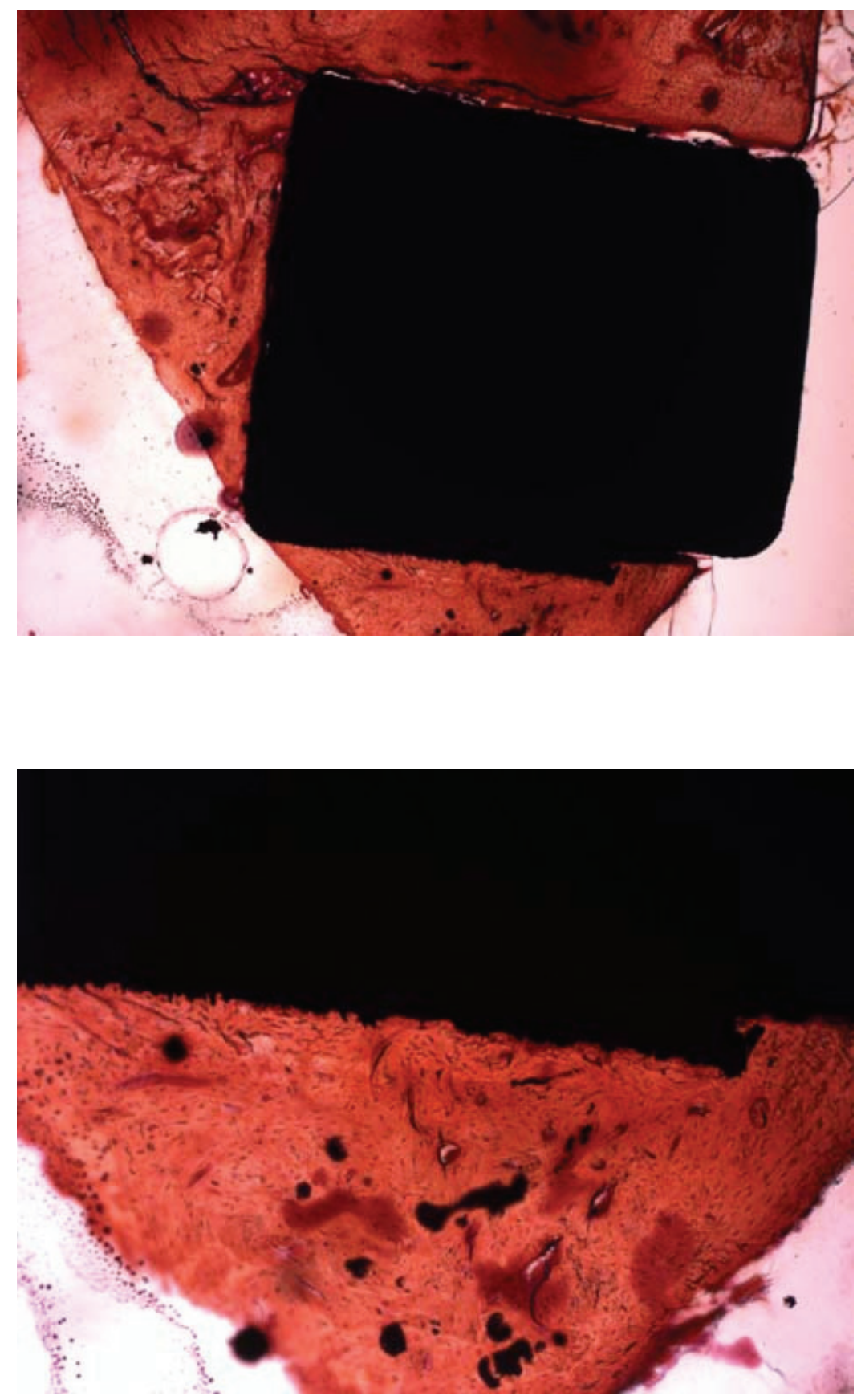

Fig. 7 Amorphous HA coated implants at nine weeks post implantation. 

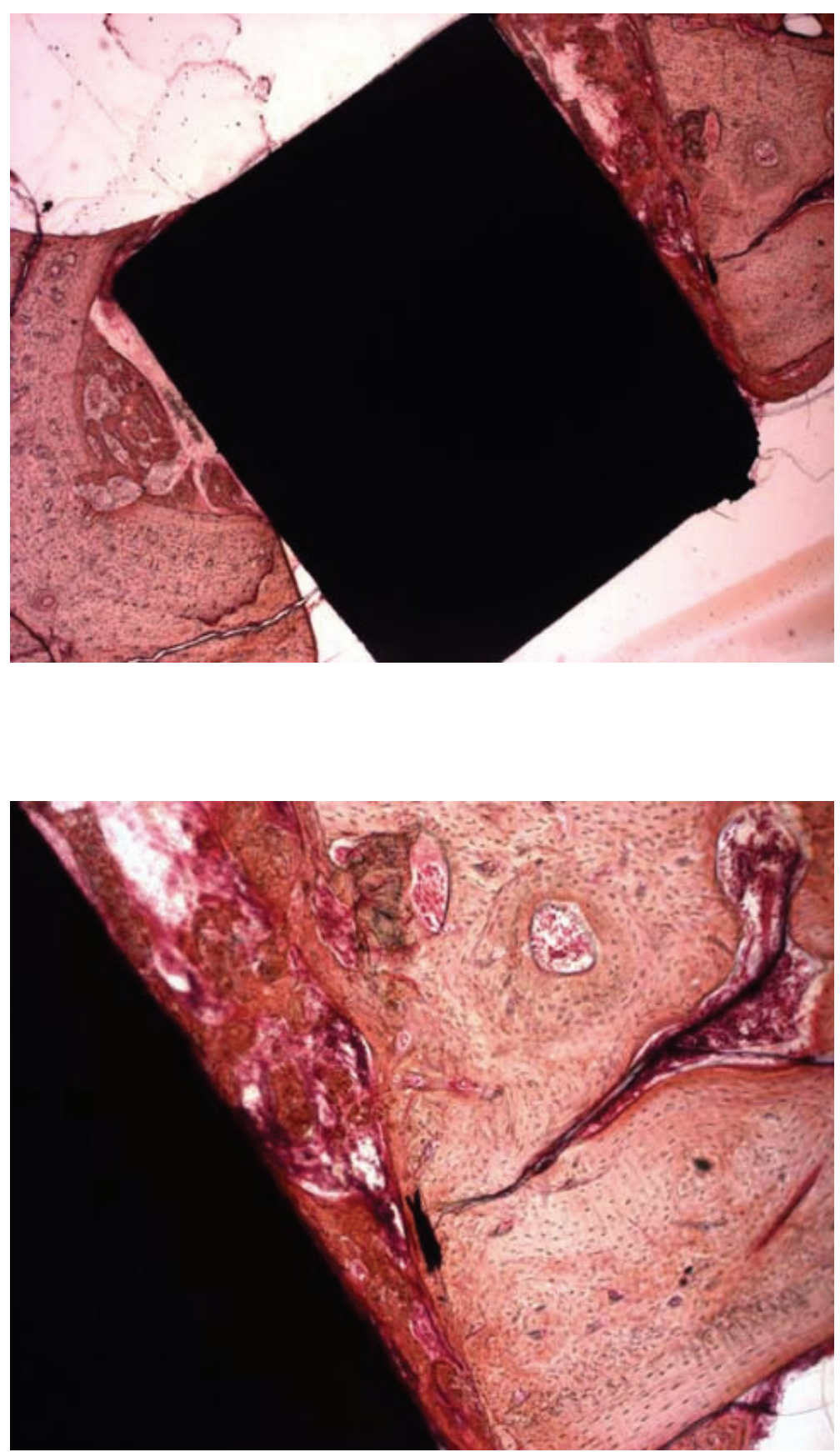

Fig. 8 Crystalline HA coated implants at three weeks post implantation. 

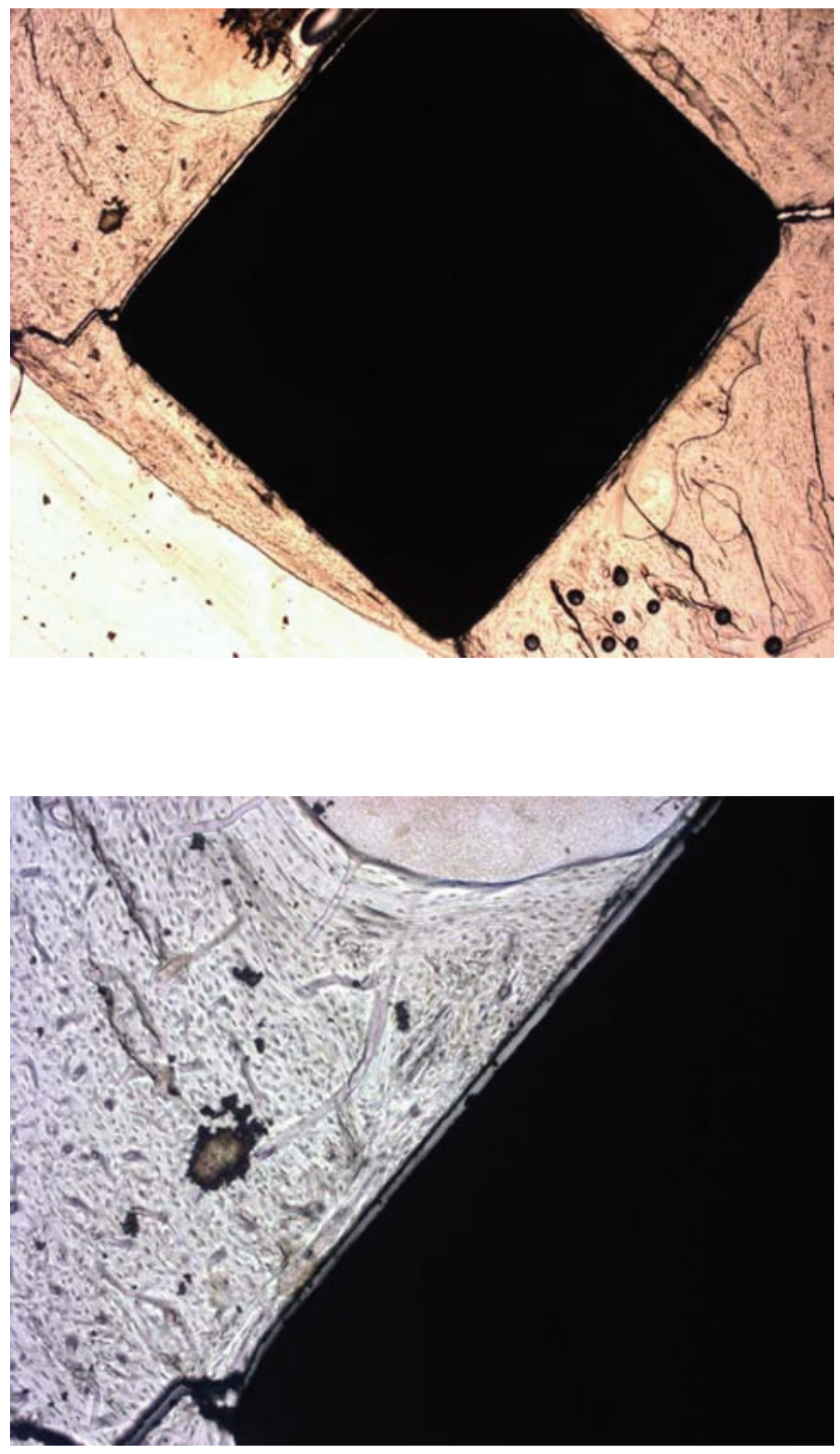

Fig. 9 Crystalline HA coated implants at nine weeks post implantation. 

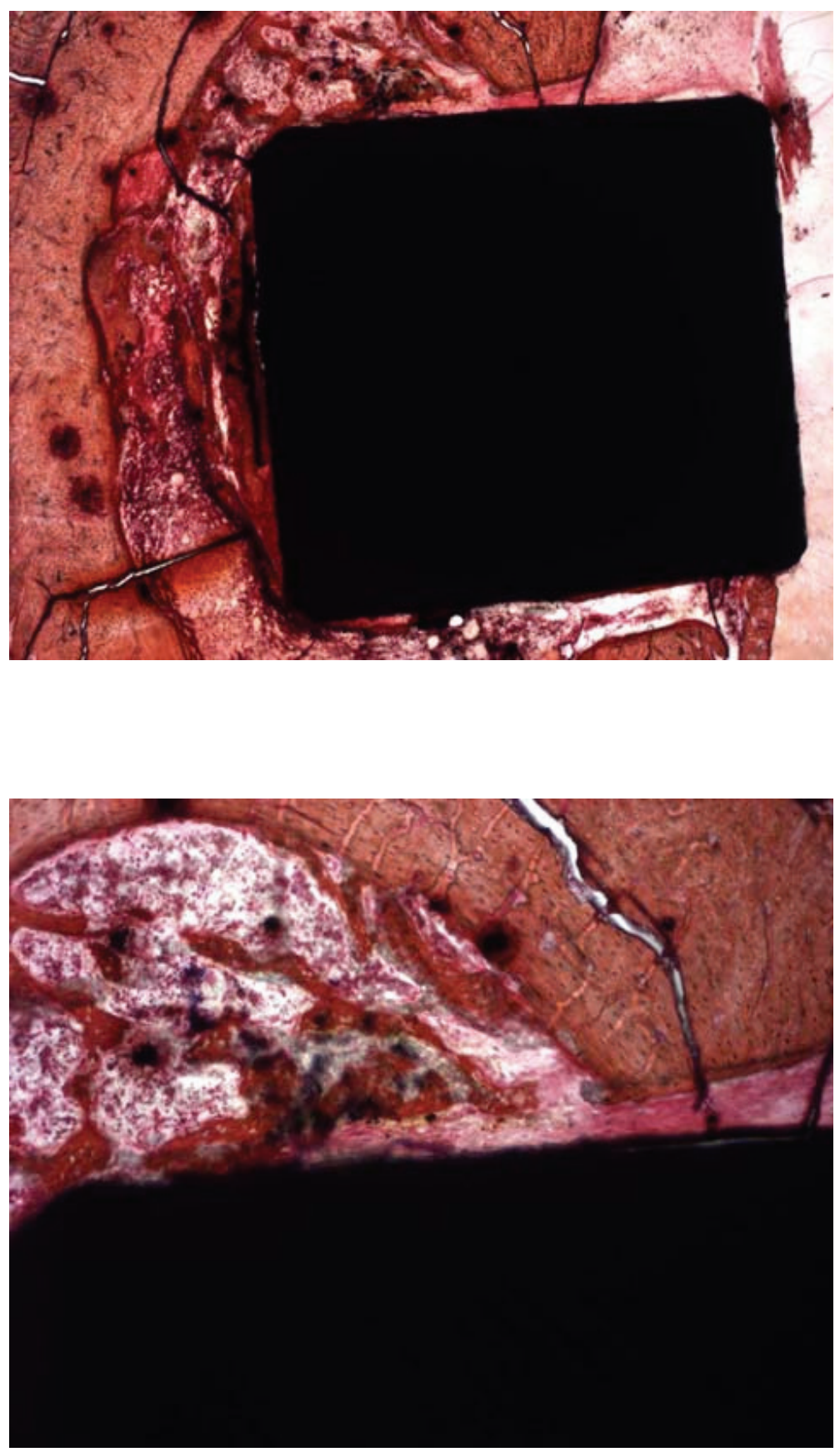

Fig. 10 Graded HA coated implants at three weeks post implantation. 

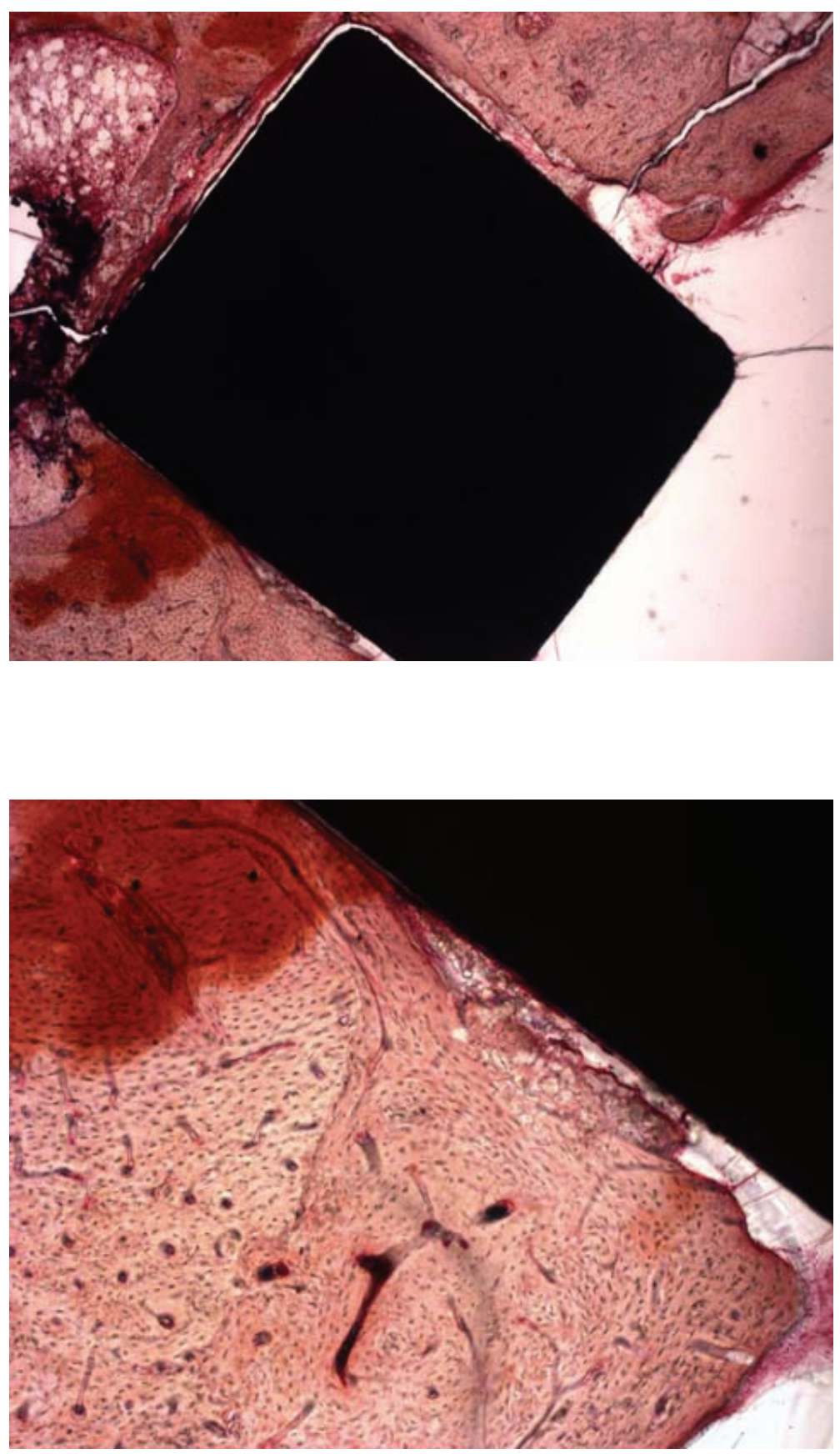

Fig. 11 Graded HA coated implants at nine weeks post implantation. 


\section{CHAPTER 6. DISCUSSION}

The concept of tooth replacement is not new. Almost since man started loosing teeth, efforts have been made to replace them. Early attempts can be attributed to the Phoenicians, Etruscans and Egyptian civilizations for making bridges to replace one or more missing teeth. The Mayan Indians carved teeth from sea shells and tapped them into the mandible, resulting in the earliest example of endosseous implants (Ring 1985).

Maggiolo introduced the more recent history of dental implants. In 1809 he used gold in the shape of a tooth root to replace missing teeth. But the early 1900's marked the beginning of the modern implant era. In 1938, Dr. Alvin Strock inserted the first vitallium dental screw implant replacing a maxillary lateral incisor. This implant lasted more than 15 years.

The major breakthrough in dental implant success came in 1952, when a physician, Dr. Per-Ingvar Brånemark and his colleagues were investigating the wound healing of titanium chambers of a screw-shaped design, inserted into a rabbit fibula. It was observed during these studies that the titanium chambers were hard to remove from the bone. These studies led to dental implant application in early 1960 (Brånemark 1983). Brånemark coined the term osseointegration, referring to the structural and functional connection between ordered living bone and the surface of a load-carrying implant. No other person in recent history has influence root form implant concepts more so than Brånemark.

Since that time, extensive research has been done to improve the osseointegration of dental implants. One of the most important factors in establishing osseointegration of an endosseous implant is the rapid formation of bone. Bone consists of organic and inorganic components. The mineral is calcium phosphate, in the form of HA crystals. When implants are placed, these components work together to heal and remodel bone after the surgical insult.

The process of osseointegration does have a timeline though. As described by Raghavendra et al. (2005), the events involved in bone apposition occur in a series of discrete but overlapping stages. First, immediately after implantation, serum proteins adhere to the implant. During the first three days, mesenchymal cells attach and proliferate. By day six, osteoid is produced, and in two weeks, matrix calcification is complete. At three weeks, remodeling of the bone is well under way. The most critical factor in successful osseointegration is primary stability in the bone at the time of implant placement, and this is easily achieved when bone is of adequate quality and volume (Raghavendra et al. 2005). Unfortunately, most patients lack this, and implants are at greater risk of not establishing primary stability. The relative motion between the implant and the surrounding bone caused by lack of primary stability is considered to be a high risk factor for early implant loss as failure of osseointegration occurs (Raghavendra et al. 2005). 
Throughout the years many materials have been used in implant fabrication. But decades of materials research have shown that commercially pure titanium (Ti) and its alloy Ti-6Al-4V are the preferred materials for human hard tissue implantation because of their strength, comparatively low stiffness, light weight, and relative inertness (Cook et al. 1987).

It has also been shown through extensive research that surface modifications on titanium implants greatly enhance osseointegration. These modifications to the implants surface geometry and /or its chemistry is effective in accelerating bone formation and achieving reliable implant fixation in less than ideal situations. Surface modifications can be subtractive, such as acid-etching or additive, using plasma sprayed HA coatings.

Hydroxyapatite coatings over titanium have enjoyed a rapid rise due to its inherent biomaterial properties. Hydroxyapatite is a calcium phosphate that is biocompatible and osteoconductive, encouraging bone already formed to lie close to, or adhere, to its surface (Sun et al. 2001). The rationale for HA coatings on implants originated from the desire to combine the strength of titanium with a bioactive HA surface (Ong et al. 2006). Sun et al. (2002) noted that HA coated implants exhibited a more rapid fixation and stronger bond between the host bone and implant. They also saw uniform bone ingrowth at the bone-implant interface.

The current popular method of deposition of HA on titanium implants is by plasma spraying or arc plasma spraying. This process produces a coating with a thickness of greater than $30 \mu \mathrm{m}$ (Ong and Chan 1999). However, problems are associated with this process. Ong et al. $(1999 ; 2006)$ reported variations in bond strength between the coatings and the metallic substrates, alterations in HA structure due to the coating process, poor adhesion between the metallic substrates and the coatings, non-uniformity in coating thickness between vendors, and non-uniformity in coating density. The thickness of the coatings can vary from 79 to $111 \mu \mathrm{m}$ (Rabiei et al. 2005). Although the biocompatible properties of HA are excellent, the brittleness of the coating often results in wear, cracking and fracture (Khor et al. 2003). In a study by Rabiei and associates (2005) it was indicated that thin HA coatings $(2 \mu \mathrm{m})$ have a significantly greater coatingmetal interfacial strength compared with commercially available thick $(70 \mu \mathrm{m})$ plasmasprayed HA coatings (40 MPa vs. 9MPa).

In the present study, bone-implant interaction of functionally graded, thin HA coatings were evaluated. These implant coatings consisted of a thin film of crystalline coating covered by a thin film amorphous coating. The thickness of the graded coating was $2 \mu \mathrm{m}$ or less. The controls were non-coated Ti, plasma sprayed HA, Amorphous HA, and Crystalline HA coatings. Push-out mechanical test were used to infer information about the interfacial bond strength between the bone and the implant interface and histological analysis was used to evaluate bone response in correlation with the interfacial strength of the implants. These tests were performed at three weeks and nine weeks post implantation. 
The push-out test results observed in the present study for graded HA coated implants was not statistically different than the control implants at three weeks after implantation, suggesting comparable interfacial bond strengths. At nine weeks post implantation all groups had increased interfacial bond strengths. The graded coated implants interfacial bond strength was greater than the Ti, crystalline HA, and amorphous HA, but not the plasma sprayed HA. This result partially supported hypothesis I in that the graded HA coated implants showed improved interfacial strength when compared to $\mathrm{Ti}$, crystalline HA, and amorphous HA, but not the Plasma sprayed HA. This was supported by the histological findings, which at three weeks, indicated the presence of connective tissues at the tissue-implant interface for all implant groups and by week nine, all HA coated implants exhibited more bone formation at the bone-implant interface when compared to the non-coated Ti implants. Qualitative assessment of bone at the interface supported the second hypothesis, revealing that plasma sprayed HA had greater bone-implant contact than the graded HA, followed by crystalline HA, amorphous HA and Ti. 


\section{CHAPTER 7. CONCLUSION}

This study determined that the ultimate interfacial bone-implant strength of all implant coatings and the non-coated $\mathrm{Ti}$ were similar at the three week post implantation period. In addition, qualitative histological evaluation of the implants at this time correlated with these findings showing mostly connective tissue at the implant interface with some new bone formation. This was to be expected at this time period. However, at nine weeks post implantation, the ultimate interfacial strength of the plasma sprayed was statistically higher than the other coated and non-coated Ti implants. The graded and crystalline coated hydroxyapatite implants resulted in statistically similar strengths due to the early dissolution of the outer amorphous layer of the graded hydroxyapatite. This dissolution caused the bone to react to the crystalline layer, thus resulting in similar pushout strengths. The amorphous hydroxyapatite coated implants and non-coated titanium implants resulted in statistically similar lowest strengths due to early dissolution of the amorphous coating. This dissolution allowed the bone to react to the titanium implant, resulting in similar push-out strengths. The qualitative analysis of the histological data at nine weeks correlated with the interfacial bone-implant results.

To date, plasma spraying is the most commonly used method of depositing hydroxyapatite coatings on titanium implants. Although it is financially feasible, the commercially available plasma sprayed coatings can substantially differ in crystallinity, thickness and surface characteristics between proprietors. Anyone of these variables can have a distinct affect on how the tissue will respond. The functionally graded coatings used in this study could possible eliminate some of the problems associated with the commercially available plasma sprayed hydroxyapatite, especially the variability of the coating thickness. Therefore, it is concluded that the functionally graded hydroxyapatite films be further studied to improve tissue-implant interfaces for medical and dental implants. 


\section{LIST OF REFERENCES}

Berube P, Yang Y, Carnes D, Stover RE, Boland EJ, Ong JL. The Effect of Sputtered Calcium Phosphate Coatings of Different Crystallinity on Osteoblast Differentiation. J Periodontal 2005; Vol.76:1697-1709.

Brånemark PI. Osseointegration and Its Experimental Background. J Prosthetic Dentistry 1983; Sept; Vol.50, No.3:399-410.

Chang YL, Lew D, Park JB, Keller JC. Biomachanical and Morphometric Analysis of Hydroxyapatite-Coated Implants with Varying Crystallinity. J Oral Maxillofac Surg 1999; Vol.57:1096-1108.

Cheang P, Khor KA. Addressing Processing Problems Associated with Plasma Spraying of Hydroxyapatite Coatings. Biomaterials 1996; Vol.17, No.5:537-544.

Clokie ML, Warshawsky H. Morphologic and Radioautographic Studies of Bone Formation in Relation to Titanium Implants Using the Rat Tibia as a Model. Int J Oral Maxillofac Implants 1995; Vol.10:155-165.

Cook SD, Kay JF, Thomas KA, Jarcho M. Interface Mechanics and Histology of Titanium and Hydroxyapatite Coated Titanium for Dental Implant Applications. Int J Oral Maxillofac Implants 1987; Vol.2, No.1:15-22.

Ferguson SJ, Broggini N, Wieland M, de Wild M, Rupp F, Geis-Gerstorfer J, Cochran DL, Buser D. Biomechanical Evaluation of the Interfacial Strength of a Chemically Modified Sandblasted and Acid-Etched Ttitanium Surface. J Biomed Mater Res 2006; Vol.78:291-297.

Irish JD. A 5,500 - Year Old Artificial Human Tooth from Egypt: A Historical Note. Int J Oral Maxillofac Implants 2004; Vol.19:645-647.

Lozada JL, Goodacre CL. Implant Dentistry, 2003. Loma Linda University School of Dentistry, Loma Linda. DVD-ROM.

Marinho VC, Celletti R, Bracchetti G, Petrone G, Minkin C, Piattelli A. Sandblasted and Acid-Etched Dental Implants: A Histologic Study in Rats. Int J Oral Maxillofac Implants 2003; Jan-Feb: Vol.18:75-81.

Oh S, Tobin E, Yang Y, Carnes D, Ong JL. In Vivo Evaluation of Hydroxyapatite Coatings of Different Crystallinities. Int J Oral Maxillofac Implants 2005; Vol.20:726731. 
Ong JL, Appleford M, Oh S, Yang Y, Chen WH, Bumgardner JD, Haggard WO. The Characterization and Development of Bioactive Hydroxyapatite Coatings. JOM 2006; July: 67-69.

Ong JL, Bessho K, Carnes DL. Bone Response to Plasma-Sprayed Hydroxyapatite and Radiofrequency-Sputtered Calcium Phosphate Implants in vivo. Int J Oral Maxillofac Implants 2002; Jul-Aug: Vol.17 (4):581-586.

Ong JL, Bessho K, Carnes DL. Evaluation of Titanium Plasma-Sprayed and PlasmaSprayed Hydroxyapatite Implants in vivo. Biomaterials 2004; Aug: Vol.19:4601-4606.

Ong JL, Chan DCN. Hydroxyapatite and Their Use as Coatings in Dental Implants: A Review. Critical Reviews in Biomedical Engineering 1999; Vol.28 (5\&6):1-41.

Rabiei A, Thomas B, Jin C, Narayan R, Cuomo J, Yang Y, Ong JL. A Study on Functionally Graded HA Coatings Processed Using Ion Beam Assisted Deposition with In Situ Heat Treatment. Surface \& Coating Technology 200 2006; 6111-6116.

Raghavendra S, Wood MC, Taylor TD. Early Wound Healing Around Endosseous Implants: A Review of the Literature. Int J Oral Maxillofac Implants 2005;20:425-431.

Ring ME. Dentistry, An Illustrated History. New York, NY, Abrams 1985; Vol.17:2845,160-179.

Ross MH, Romell LJ, Kaye GI. Histology: A Text and Atlas. Philadelphia: Lippincott Williams \& Wilkins, Third Edition 1995; 150-169.

Sun L, Berndt CC, Gross KA, Kucuk A. Material Fundamentals and Clinical Performance of Plasma-Sprayed Hydroxyapatite Coatings: A Review. J Biomed Mater Res 2001; Vol.58:570-592.

Sun L, Berndt CC, Khor KA, Cheang HN, Gross KA. Surface Characteristics and Dissolution Behavior of Plasma-Sprayed Hydroxyapatite Coating. J Biomed Mater Res 2002; Vol.62:228-236.

The American Dental Association, Current Dental Terminology. Chicago: The American Dental Association, Second Edition 1995-2000; 72.

Trisi P, Keith D, Rocco S. Human Histologic and Histomorphometric Analyses of Hydroxyapatite-Coated Implants after 10 Years of Function: A Case Report. Int J Oral Maxillofac Implants 2005; Vol.20:124-130.

Worthington P., Lang B., Rubenstein J. Osseointegration in Dentistry. Chicago: Quintessence Publishing Co., Inc. 2003; 3-5. 
Yang Y, Dennison D, Ong JL. Protein Adsorption and Osteoblast Precursor Cell Attachment to Hydroxyapatite of Different Crystallinities. Int J Oral Maxillofac Implant 2005; Vol. 20:187-192.

Zechner W, Tangl S, Furst G, Tepper G, Thams U, Mailath G, Watzek G. Osseous Healing Characteristics of Three Different Implant Types. Clin Oral Implants Res 2003; Apr: Vol.14(2):150-157. 


\section{VITA}

Dr. Suzanne Kemp Coco was born on July 20, 1965. She received her D.D.S. degree from the University of Tennessee Health Science Center, College of Dentistry in 2005. She was accepted into the University of Tennessee Health Science Center Advanced Prosthodontic program while an undergraduate at UT. Dr. Coco is currently a third year resident, specializing in fixed and removable prosthodontics at UTHSC. She is also working toward her Master of Dental Science degree from the University of Tennessee. While in dental school she was invited to join the Honorary Odontological Society, University of Tennessee, College of Dentistry. She is a current member of the American College of Prosthodontists, American Dental Association and the Arkansas State Dental Association. 